\title{
To the article
}

\section{"Coherent Fluctuation Nephelometry: A Rapid Method for Urine Screening for Bacterial Contamination,"}

\section{by A. S. Gur'ev, A. Yu. Volkov, I. I. Dolgushin, A. V. Pospelova,}

S. F. Rastopov, A. Yu. Savochkina, and V. I. Sergienko,

\section{Vol. 159, No. 1, pp. 107-110, May, 2015}

On page 107 , in the $18^{\text {th }}$ line of the first column, the term "optical nephelometry" should be replaced with "nephelometry."

On page 107 , in the $6^{\text {th }}$ line of the second column, "stringent limitations for the number of cuvettes" should be replaced with "stringent requirements on the quality of cuvettes."

On page 107, in the $15^{\text {th }}$ line of the second column, "The work of CFN instrument" should be replaced with "The functioning of CFN instrument."

On page 108 , in the $12^{\text {th }}$ line of the second column, "at least $2 \mathrm{~h}$ before" should be replaced with "not more than $2 \mathrm{~h}$ prior to." 